\title{
COVID-19 as a framing device for environmental protest: the ECOSYSTEM HEALTH metaphor
}

\author{
Anaïs Augé \\ University of East Anglia
}

\section{7,800 words}

\begin{abstract}
:
This paper focuses on the ECOSYSTEM HEALTH metaphor which has long prevailed in environmental communication. Following the global impact of the COVID-19 pandemic, we propose a contrastive view on the use of the ECOSYSTEM HEALTH metaphor in environmental discourse: we distinguish the metaphorical expressions used before the pandemic from the ones used during the pandemic. This distinction is aimed at identifying the new arguments promoted by COVID-19 metaphors. The publications released by the international environmental organisation Extinction Rebellion are of particular interest. Through a detailed analysis of texts published between January and July 2020, we show that the impact of COVID-19 has modified our understanding of the ECOSYSTEM HEALTH metaphor. While environmentalists used to depict the environment as a SICK BODY prior the pandemic, the occurrences discussed below demonstrate that COVID-19 metaphors highlight the human characteristics associated with the source domain HEALTH.
\end{abstract}

Keywords: Ecosystem health, metaphor, COVID-19, Extinction Rebellion, climate change

\section{Introduction}

With the surge of the Coronavirus, the media attention significantly shifted towards health issues. This unforeseen phenomenon triggered large-scaled reactions including enforced lockdown and interruption of activities. In this paper, we investigate the consequences of the virus on environmental communication.

A brief research on the Nexis database (n.d.) shows that the number of newspaper articles whose headlines include the phrases "climate change" or "global warming" have decreased since March 2020: we found 6,580 British newspaper articles discussing this topic between January $1^{\text {st }}$ and March $1^{\text {st }} 2020$ whereas we only found 4,363 articles published between March $1^{\text {st }}$ and July $1^{\text {st }} 2020$.

We demonstrate how metaphors enabled activists to include COVID-19 within environmental discussions. The questions addressed in this research are related to the link between health and the environment. Such a link is explicitly advertised by the ECOSYSTEM HEALTH metaphor which prevails in environmental communication. We ask to which extent COVID-19 has shifted environmental arguments promoted by the ECOSYSTEM HEALTH metaphor. 
We focus on a specific environmental movement, Extinction Rebellion (XR), known for its international influence and its spectacular protests facilitating wider communication about climate change. These mass protests distinguish XR from other environmental organisations: activists attract media attention through peaceful disturbances (blocking streets and businesses), and eye-catching performances like the Red Brigade's parade involving protesters dressed in red gowns. This communicative strategy effectively attracted attention: 50 newspaper articles explicitly focused on the Red Brigade during XR's protest in October 2019 (following a research on Nexis with the keywords "Extinction Rebellion" and "Red Brigade"). This protest was aimed at "shutting down" London and it gathered over 6,000 protesters. While XR remains a relatively new organisation officially established in the United Kingdom in 2018 - its influence spread globally: in 2020, 1,136 affiliated groups and 250,000 "rebels" were established in 72 countries.

The enforced lockdown made it necessary for XR to change their main communicative strategies. This paper demonstrates how metaphors have been part of this change.

\section{The ECOSYSTEM HEALTH metaphor: definition(s) and interpretation}

\subsection{What is a metaphor?}

Metaphors prevail in environmental discourse. They help metaphor users to explain and popularise environmental concepts (Nerlich and Hellsten 2014). This paper draws on two key metaphorical aspects: revitalisation and scenarios. We develop the hypothesis that metaphorical references to COVID-19 may revitalise the ECOSYSTEM HEALTH metaphor in XR's communication. We ask whether this hypothesised revitalisation has an argumentative function perceived through the metaphor scenario ENVIRONMENTAL DISRUPTION AS COVID-19. The "revitalisation" offers a pragmatic approach to metaphor. This pragmatic approach establishes how the topic can be perceived from a new perspective, which emerges from the use of revitalised metaphors. Scenarios are related to pragmatic, conceptual, and communicative views on metaphor: these reveal that this new perspective may be associated with different arguments about the topic (see below).

Metaphors result from a mapping between a complex target domain (i.e., the topic of discourse) and a more familiar source domain (i.e., the "alien" concept within the discourse; Lakoff 1993). The similarities between the source and target are described as "the ground" of the metaphor (Lakoff 1993; Goatly 1997). For example, the metaphorical expression greenhouse effect describes the warmth experienced on earth, which is metaphorically related to the warmth experienced within a greenhouse (Nerlich and Hellsten 2014).

The association of domains can also be discussed with reference to (un)conventional metaphors, resulting from (un)conventional mappings of domains. Notably, Goatly (1997) shows that metaphors can be "dead", "inactive", or "active":

The further one proceeds down the figure from Dead to Active, the more likely that the expressions will be processed as metaphors, that is, that the item will be recognized as a V-term [related to the source domain], and Grounds will be constructed. (Goalty 1997: 31; our addition in square brackets) 
"Active" metaphors can be pragmatically decoded by the recipient and the ground of the mapping has to be created (Goatly 1997: 35), the domains are not commonly mapped: for example, "his tractor of blood stopped thumping" (Goatly 1997: 32). "Inactive" metaphors convey a relatively salient figurative meaning (Goatly 1997: 33 ), the ground of the mapping is fixed by habit or convention: for example, a person called a rat is disloyal (Goatly 1997: 32). "Dead" metaphors rely on a mapping that is not acknowledged any more, the ground does not exist: for example, pupil refers to a student (Goatly 1997: 32).

"Dead" and "Inactive" metaphors can be "revitalised": "In Revitalization, we have an attempt to reforeground metaphors which have become so well established that they have faded in the background" (Goatly 1997: 289). The "revitalisation" occurs when metaphor users refer to new, unnoticed characteristics of the domains to establish a new ground. For example, the metaphorical compound carbon footprint (Nerlich and Hellsten 2014) has been compared with the less conventional metaphorical expression carbon Bigfoot, which describes the entity who left the footprint instead of the footprint itself (Koteyko, Thelwall, and Nerlich 2009: 43).

Goatly's distinction between "active", "inactive", and "dead" metaphors is established through pragmatic experiments involving participants. Our analysis of environmental communication does not allow us to determine whether the ECOSYSTEM HEALTH metaphor belongs to a specific pragmatic category. However, we can determine that the ground of the mapping ENVIRONMENTAL DISRUPTION AS COVID-19 has yet to be created, acknowledging the recent discovery of the source concept. While the domain HEALTH comprises a wide variety of characteristics (e.g., fever, cold, surgery), COVID-19 limits these characteristics to a specific, recent disease. We can thus speculate that COVID-19 metaphors may be more "active" than other HEALTH metaphors in environmental communication.

The distinctive characteristics of COVID-19 are of particular interest: we ask whether such characteristics can promote new environmental arguments, perceived through HEALTH metaphors.

Existing literature shows that the source domain of a metaphor (e.g., HEALTH) can promote different arguments in discourse. For example, in a corpus of European political debates, Musolff (2016) analyses the metaphor NATION AS BODY. His research shows that this metaphor was used as a political argument to define the place of Britain within Europe. For instance, the former British Prime Minister John Major claimed that Britain was at the heart of Europe. The British press disputed this claim through another BODY metaphor, placing Britain at the end of a limb (Musolff 2016: 41-5). The varying use of a source domain to communicate about a disputed topic reveals particular metaphor scenarios. Scenarios involve assumptions about the source concept: this source concept becomes part of a metaphorical script to promote a certain evaluation of the topic (Musolff 2016: 30-1). Hence, the descriptions placing Britain at the heart of Europe or at the end of a limb are related to the metaphor NATION AS BODY. Metaphor users relied on different characteristics of the source concept BODY in order to promote opposite arguments: assumptions about the heart differ from assumptions about the limb, and these produce different evaluations. Accordingly, associated arguments may refer to a rotten heart or to a blood clot to describe European issues (Musolff 2016: 45). Scenarios are not limited to the exploitation of the source domain; they are included in contexts which involve various arguments about the target.

\subsection{The ECOSYSTEM HEALTH metaphor}


The complexity of climate change requires a delimitation of our analysis to particular target domains (temperatures, pollution, policies) or particular source domains. Metaphor scholars have either investigated a particular aspect of climate change - Nerlich (2010) focuses on climate change scandals; Koteyko (2010) focuses on pollution; Flusberg, Matlock, and Thidodeau (2017) focus on climate policies - or particular source concepts associated with the topic. The latter approach is relevant to our study which analyses the use of the source domain HEALTH in publications from XR. Researchers share many findings about the source domains associated with climate change. For example, media discourse about climate change presents many WAR and RELIGION metaphors (Atanasova and Koteyko 2017). WAR metaphors highlight the lethal consequences of the concepts of WAR and CLIMATE CHANGE: "When will Americans start to combat excessive energy use and kill the problems?" (Flusberg, Matlock, and Thibodeau 2017: 772). WAR metaphors picture humans in the same CAMP to advertise appropriate actions (Atanasova and Koteyko 2017: 464-5). Comparatively, RELIGION metaphors favour sceptical arguments: "They [G8 leaders] are like medieval preachers proclaiming to baying crowds at the end of the world in nigh" (Atanasova and Koteyko 2017: 460, our addition in square brackets). The uncertainty related to religious beliefs is mapped to the uncertainty related to climate change (Nerlich 2010). Foust and Murphy (2009) show that RELIGION metaphors can sometimes be part of counterarguments: these may present scientists as prophets who interpret signs (2009: 153-6). These studies demonstrate that a source domain can be exploited in environmental discourse to advertise different arguments.

Ross et al. (1997) show that the ECOSYSTEM HEALTH metaphor has become more and more prevalent in environmental discourse since the $20^{\text {th }}$ century (1997:115). This metaphor illustrates the relationship between humans and the environment with HEALTH-related expressions: it emphasises human dependence on nature. Metaphorical references to the SYMPTOMS, DIAGNOSIS, or TREATMENT of the environment can advertise suitable solutions to ecological problems (1997: 123). This metaphor can be identified in occurrences such as "An ecological system is healthy and free from distress syndrome if it is stable and sustainable" (1997: 119), "[The ecosystem approach] directs the efforts of the parties and Commission toward treatment of the patient (the Ecosystem), rather than the symptoms or disease" (1997:124; our addition in square brackets).

The ECOSYSTEM HEALTH metaphor comprises a wide variety of features which can be mapped to climate change or the environment:

\section{ENVIRONMENT AS A BODY}

ENVIRONMENTAL RESOURCES AS BODY PARTS

POLLUTION AS A DISEASE

\section{POLLUTED ENVIRONMENT AS A DISEASED BODY}

CLIMATIC EVENTS AS SYMPTOMS

CLIMATE SOLUTIONS AS TREATMENT

Within this range of metaphorical mappings, the source domain can be exploited in various ways (e.g., different DISEASES, different TREATMENTS). This exploitation depends on the metaphor user's stance on climate change. For example, HEALTH metaphors can share a dramatic stance: the signs of the ecosystem's AFFECTED HEALTH are associated with environmental threats ("healing the planet", "nature is dead"; Rapport 1995: 288). 
HEALTH metaphors can also be associated with the personification of nature ("Mother Nature"). This personification promotes emotional bonds between metaphor recipients and the ecological system. The HEALTH CONDITIONS of Mother Nature can raise concerns regarding environmental damages (e.g., "Mother Nature is in dire peril"; Augé 2019: 218). Overall, the ECOSYSTEM HEALTH metaphor advertises the possibility of a sustainable environment (Larson 2011) and facilitates communication to non-scientists (Ross et al.1997: 119-20).

Acknowledging the ground of the ECOSYSTEM HEALTH metaphor, the source domain HEALTH can map with many aspects of climate change. The metaphorical references to COVID-19 may "reforeground" a wellestablished metaphor (Goatly 1997) in publications from XR and these may promote specific arguments.

\section{Methodology}

To demonstrate how COVID-19 has been used as part of the ECOSYSTEM HEALTH metaphor, we analyse texts retrieved from Extinction Rebellion's website, available in the "News" section. We focus on texts which were published between January $1^{\text {st }}$ and July $1^{\text {st }}, 2020$. Our methodology comprises three main steps: 1) distinguishing metaphorical from literal expressions, 2) establishing an initial list of keywords associated with COVID-19, and 3) testing the semantic relation between the metaphorical expressions in publications from XR and the source domain HEALTH.

\subsection{Metaphorical or Literal expressions}

After a manual analysis of all publications, we observed several expressions which may have been used metaphorically. Our first step was to establish whether an expression is metaphorical or literal. We relied on the Metaphor Identification Procedure (Steen et al. 2010):

- read texts and identify an "alien" word,

- search for a more "basic" meaning of this word,

- if this "basic" meaning differs from the contextual meaning (the meaning of the word in the text), identify the metaphorical mapping (Steen et al. 2010).

For example, the sentence "the earth is affected by coronavirus" can be interpreted according to a metonymy THE EARTH FOR ITS INHABITANTS - instead of a metaphor. However, in the context, we observe a visual representation of the Earth wearing a mask on which the word "coronavirus" is displayed (Newsletter 38, 08/04/2020). This instance can thus be interpreted as a metaphor.

\subsection{Identification of keywords related to COVID-19}

Our second step was to perform a research on an electronic corpus, the British National Corpus, accessed from SketchEngine (Kilgarriff 2014). This resulted in the identification of expressions related to COVID-19. In contrast, our third step (following sub-section) focuses on the expressions related to HEALTH.

The BNC was used to identify particular keywords associated in context with the concept COVID-19. The BNC highlighted the contextual link existing between COVID-19/Coronavirus and the words "lockdown", 
"mask", "safety", "isolation", and "distancing". This contextual link was established following an analysis of the contextual uses of the word "COVID-19" or "Coronavirus" in the examples provided by the BNC. These results yielded an initial (but non-exhaustive) list of keywords which can be semantically associated with the domain COVID-19. These words have then been searched in the texts published by XR in order to observe possible metaphorical uses.

\subsection{Semantic relation between expressions in context and HEALTH}

Our manual analysis of XR's publications led us to identify a plurality of metaphorical expressions. Our paper discusses the arguments promoted by HEALTH metaphors related to COVID-19 and the arguments promoted by HEALTH metaphors unrelated to COVID-19. We thus needed to determine whether the metaphorical expressions in these publications could be associated with the source domain HEALTH.

We used the WordSketch function of SketchEngine. This function shows the most frequent collocates of a particular keyword. These collocates establish a link between the expressions identified in XR's publications (used as keywords) and the domain HEALTH. Indeed, some occurrences observed in XR's publications like "we need to save the planet" and "we will protect the environment" raised doubts about the semantic relation between words like "save" and "protect" and the domain HEALTH.

The definitions from the Oxford English Dictionary cannot solve these interpretative issues. The definitions of "save" are "to rescue, preserve, or protect; to get oneself out of danger, difficulty" (definitions I. 2.a. to I.2.f.; I.3.b.c.; I.5.a.). The definitions of "protect" are "to defend, to guard from danger or injury; to support or assist against hostile or inimical action" (definitions 1.a.; 2; 3.a.; 5).

Firstly, we used "save" and "protect" as keywords on WordSketch. We could then identify the most frequent contexts (e.g., HEALTH-related contexts or other contexts) in which these keywords are generally included. The results determined whether the collocates of "save" and "protect" are related to human health or to different domains.

The results for the word "save" established that the collocate "life" is the most frequent object of the verb (587 results). However, the other collocates refer to non-human, material and immaterial entities like "money", "energy", "time", and "file". Comparatively, the results for the word "protect" seemed slightly more related to the domain HEALTH, with collocates such as "public", "child", "citizen", "health". However, several collocates refer to non-human entities like "interest", "right", "property", and "investment".

Secondly, we performed a more detailed analysis of the contextual information provided by WordSketch. We observed the different contexts which rely on the collocations aforementioned. This analysis distinguished HEALTH-related contexts from contexts unrelated to HEALTH. For example, the contextual information related to the collocations of "save" and pronominal objects like "yourself" and "him/her(self)" does not systematically describe human health: "That way, you can save yourself a whole load of trouble" (token 2134632); "I'll be watching carefully tomorrow to see if any player is saving himself for the semi-final" (token 12190829). Similarly, the contextual information related to the collocations of "protect" and words referring to human participants does not systematically describe human health: "Conservative Members wish to protect the public further from trade union activities" (token 15132333). Alternatively, descriptions may only be indirectly related to health: "Where 
the court makes a residence order in care proceedings a family assistance order will not be appropriate if there is a need to protect the child and provide local authority services" (token 3331882).

Thirdly, after the analysis of the collocates and contextual uses of save/protect, we determined whether save and protect were frequently associated with HEALTH-related contexts (according to the results provided by WordSketch). If the contextual information revealed frequent associations between save/protect and HEALTH, then the uses of save/protect in XR's publications could be considered as instances of HEALTH metaphors. If the contextual information revealed sporadic associations between save/protect and HEALTH, then the uses of save/protect in XR's publications could not be considered as instances of HEALTH metaphors. The semantic relation between the verbs "save" and "protect" and contexts related to HEALTH remains too ambiguous to include instances such as "save/protect the environment" in this study. The call to save or protect the environment possibly implies that the environment is endangered. Yet, WordSketch shows that this endangerment may not systematically be related to the ECOSYSTEM HEALTH.

XR may occasionally specify the metaphorical meaning of the expressions used in their publications. In such cases, the details provided in the publications can highlight an association with the source domain HEALTH (expressions can thus be interpreted as HEALTH metaphors). For example, "we need to protect the environment from the Coronavirus".

The details of our corpus are as follow:

Table 1: Details of the corpus

\begin{tabular}{|l|c|c|}
\hline & Articles not mentioning COVID-19 & Articles mentioning COVID-19 \\
\hline Number of publications & 101 & 116 \\
\hline $\begin{array}{l}\text { Occurrences of HEALTH } \\
\text { metaphor }\end{array}$ & 27 & 31 \\
\hline
\end{tabular}

The scope of our research is corpus-based (Tognini-Bonelli 2001). We do not aim at providing an exhaustive account of the ECOSYSTEM HEALTH metaphor in publications from XR. Our approach favours a qualitative analysis to identify the particularities of COVID-19 metaphors compared with other HEALTH metaphors. Table 1 provides an overview of the frequency of HEALTH metaphors in our corpus. We notice that the use of HEALTH metaphors by XR has not particularly increased during the pandemic.

In the following section, we discuss the HEALTH metaphors unrelated to the pandemic to compare them with COVID-19 metaphors.

\section{The HEALTH metaphors unrelated to the pandemic}

\subsection{The HEALTH of the planet}

We first analyse HEALTH metaphors which are not related the pandemic. These metaphors were mostly observed in publications released before the pandemic was declared by the World Health Organisation, in March 2020. We analyse texts which do not mention COVID-19 - metaphorically or literally - and we study XR's use of HEALTH metaphors prior the pandemic.

We observe that these HEALTH metaphors do not rely on specific source domains, like specific DISEASES or TREATMENTS characterising environmental disruptions. For instance, activists call readers to 
keep the planet healthy:

"The environment and the health of our planet are in the hands of you and I" ("The planet needs actions, not words", 01/03/2020)

This extract describes the planet as a BODY whose HEALTH needs to be taken care of ("in the hands of you and I"). This emphasises that, like a BODY, the planet needs protection. This extract does not explicitly mention that the planet is SUFFERING FROM HEALTH ISSUES. This absence of pathos may seem surprising because activists are aware of the present climatic conditions. However, XR promotes particular arguments through the general reference to the HEALTH of the planet. They advertise humans' responsibility in keeping the planet HEALTHY. "The health of our planet" reminds readers of the various actions performed to take care of their own bodies. XR argues that these actions should also apply to the planet. The absence of pathos highlights the ease with which we could take care of the PLANET-BODY, compared with the ease with which we take care of our own bodies. This easy aspect can be observed in the metaphorical shrinking of the health of the planet: it materialises into an object we can hold in our hands.

Other HEALTH metaphors share contrastive views on the effects of anthropogenic climate change. On the one hand, occurrences emphasise the dramatic consequences of human activities:

"The twin themes of this year's WEF [World Economic Forum] were 'sustainability' (i.e. ending the death spiral of our living planet) and 'cohesion' (i.e. ending the insane levels of inequalities that blight our society)" ("Speaking truth to obscene wealth", 01/02/2020)

In this extract, the planet is still described as a LIVING BODY ("living planet"). However, this view is contrasted with the "death spiral" it is experiencing. The contrast between "living" and "death" highlights the scale of the degradation: the planet is not depicted as SUFFERING or SICK, it is described as DYING. This detail is essential to understand XR's argument: it shows that the lack of sustainability is KILLING the PLANET-BODY. The absence of a metaphorical HEALTH ISSUE at the origin of the DEATH SPIRAL attracts readers' attention towards the impact of sustainability: if sustainability prevails, it allows the PLANET-BODY to LIVE, but if sustainability is neglected, the PLANET-BODY will DIE. This dilemma emphasises the significance of the discussions taking place during the WEF. Additionally, the expression "spiral" adds more pathos to the interpretation: the "death spiral" characterises the present state of the PLANET-BODY which struggles between life and death. The use of the expression "death spiral" instead of a gerundive like "dying" characterises this struggle as never-ending: this conveys nightmarish images of a BODY which has been between life and death for years. Even though the source and target domains are not specific ("planet"; "living"; "death spiral"), the metaphor can still effectively persuade recipients that sustainability is vital.

On the other hand, metaphors can promote a more optimistic view through depictions of the planet as a BODY SURVIVING damages. An explicit instance can be observed in the short film "Guardians of life" available on XR's website (Jamie Lowe, 06/02/2020, 3:35 minutes). In this film, we can see surgeons trying to save a body which eventually dies in an operating room. By the end, a nurse resuscitates the body: we now see that the body is represented by aerial views of Brazil and Australia on fire. This visual HEALTH metaphor first maps the fires in 
Brazil and Australia with a BODY SUFFERING FROM GRAVE DAMAGES: the BODY is so affected that it needs a surgical intervention. This alarmist view echoes the LETHAL/ENDANGERING characteristics of the source and target domains. The first half of the film can be interpreted as a metonymy: THE DYING BODY FOR THE PEOPLE WHO DIED IN THE FIRE. In the second half, the DEATH and RESURRECTION OF THE BODY call viewers to keep acting upon fires and deforestation: the video shows surgeons progressively leaving the operating room after the BODY DIED while a nurse decides to try CPR and RESUSCITATES THE BODY. The motions of the camera, the long focus on the nurse's emotions, and the final resurrection influence viewers to identify with the nurse. The surprise following the RESURRECTION is highly persuasive: the viewers' emotions related to the DEATH - echoing viewers' experience of LOSS - promote a feeling of relief when the BODY is saved. This relief is then associated with the possible consequences of international actions to save Brazil and Australia.

Other HEALTH metaphors (unrelated to COVID-19) differ from the occurrences aforementioned. These metaphors are less typical instances of the ECOSYSTEM HEALTH: these are AGGRESSION/MURDER metaphors.

\subsection{The AGGRESSION of the planet}

This second metaphorical theme is only indirectly related to the ECOSYSTEM HEALTH metaphor. Yet, these occurrences are relevant because they depict the planet as a BODY. Here, the PLANET-BODY does not suffer from DISEASES/PAIN/SYMPTOMS but from an AGGRESSION/MURDER. For example, pollution from industries is sometimes described as an ECOCIDE:

"This is a story of Ecocide. This could be just as easily Exxon, BP, or any of the giant corporations who are putting profits before wellbeing and regeneration" ("Rebel Radio Special: Dark Waters", 22/02/2020)

The ECOCIDE metaphor relies on the morpheme "-cide" which is more commonly applied to crime-related words such as "homicide", "feminicide", and "genocide". The morpheme preceding "-cide" refers to the victims of the crime (humans). An ECOCIDE belongs to a category of CRIME which results in the MURDER OF THE ECOSYSTEM. The cognitive association with other types of MURDER adds a highly emotional perspective to the ECOSYSTEM DEATH. Unlike the metaphor THE PLANET AS A DYING BODY, the ECOCIDE focuses on the COMMITTED CRIME instead of the pathetic state of the VICTIM. An ECOCIDE implies that the CRIME is already COMMITTED: the ecosystem is already DEAD and cannot REGENERATE. The impossibility to CURE the ecosystem limits the actions that can be undertaken to respond to this CRIME. The only solution left is the identification of the CULPRITS: "Exxon, BP, or any of the giant corporations". XR's argument relies on the emotional impact of the morpheme "-cide" and on the social response commonly applied to such a CRIME: the CONVICTION OF THE CULPRITS. However, XR's depiction of the DEAD ECOSYSTEM neglects various actions which individuals can take to save the environment (e.g., sustainable consumption). This metaphor is comparable to other occurrences which depict pollution as an AGGRESSION HARMING the environment, polluting sectors as CRIME SCENES, and polluters and companies as CRIMINALS.

XR has extended the ECOSYSTEM HEALTH metaphor to involve the sectors, companies, and humans responsible for the HEALTH DEGRADATION. These AGGRESSION/MURDER metaphors emphasise the 
extent of environmental disruption and blame responsible communities for this disruption. Compared with HEALTH metaphors, the AGGRESSION/MURDER metaphors share a wider ground with climate change because both domains involve human causes.

In the following section, we focus on the specific use of COVID-19 metaphors in publications from XR.

\section{The ECOSYSTEM HEALTH metaphor and COVID-19}

\subsection{ENVIRONMENTAL SAFETY MEASURES AS COVID-19 SAFETY MEASURES}

Following global concerns related to the pandemic, XR has highlighted a wide range of correspondences between the virus and ecological disruption. Activists emphasise that the decrease of the number of people affected by the virus is not an end to the threats humanity faces.

Preventive actions were notably lacking in the management of the health sector. The pandemic has highlighted existing gaps in health management. Accordingly, XR metaphorically links health improvement to the prospective improvement of the ENVIRONMENTAL HEALTH.

"Healthy people need a healthy environment. Do you want to have good health?" (Newsletter 14 , 20/05/2020)

This extract refers to the recent increase of attention towards health issues. XR does not explicitly associate people's health with COVID-19. The lack of explicit information about COVID-19 fulfils argumentative functions: COVID-19 mitigation is only perceived as a means to an end. XR relies on our recent acknowledgement of the limits of human health: activists emphasise that these limits will again be approached if our environment is not HEALTHY. The lack of explicit reference prevents readers from believing that health management has satisfactorily improved, following COVID-19 mitigation. This denial promotes a continuous global interest in health issues. According to XR, this continuous interest would yield a global recognition of the link existing between humans' health and ENVIRONMENTAL HEALTH. The question "do you want to have good health?" relies on the recent fear experienced globally. It emphasises that the reality of "good health" can still be questioned because the ENVIRONMENTAL HEALTH is insecure. XR uses people's time-limited relief promoted by the decrease of infected people - to advertise a possible long-lasting relief. This possibility can only become real if the ENVIRONMENTAL HEALTH is taken into account. The metaphor pictures the environment as a BODY which experiences HEALTH ISSUES - comparable to people's recent experience - but its HEALTH has not yet been taken care of. This lack of management of ENVIRONMENTAL HEALTH implies that the sources of health issues (like the pandemic) are still present in humans' neighbourhood and can affect humanity again. Hence, the focus is not only on the environment, but also on the benefits of a HEALTHY ENVIRONMENT for humans.

The particularities of the safety measures preventing the spread of the virus have also been applied to environmental issues. According to XR, these unprecedented actions should continue not only to tackle the pandemic but also to tackle pollution. Several occurrences rely on the mapping POLLUTION AS 


\title{
VIRUS/INFECTED ENTITIES.
}

\author{
"Warning! Wash your hands of fossil fuels!" \\ "No going back: Unmask the bigger problem!" (Newsletter 14, 20/05/2020)
}

The communication about the necessity to wash hands regularly and to wear masks during the pandemic has been adapted to warn about the danger of pollution. In the first slogan, fossil fuels are identified as infected items which can endanger life in case of direct contacts. The slogan presents the use of fossil fuels as a self-inflicted infection. This argument stems from the depiction of fossil fuels as a danger to human health, but humans' consumption prevents an eradication of this danger. The metaphor WASHING HANDS illustrates the daily use of fossil fuels: fossil fuels are contained in items which people regularly use, like virus particles can be found on every item. This metaphor may be favoured over other possible metaphors (we can infer that a VACCINE is more effective in preventing the spread of the virus) because its source domain involves a repeated action that people take to avoid infection. This slogan argues that fossil fuels are as dangerous as the virus, and the mitigation of this danger requires daily, repeated actions.

In the second slogan, the arguments differ: XR does not refer to the protective properties of the masks but to people's increasing familiarity with this item (which was sporadically used in Western countries before the pandemic). The masks protect humans by covering body parts that can transfer the virus. XR focuses on the covering strategies performed by polluting sectors, industries, and industrial supporters to hide their pollution. Activists argue in favour of transparency, calling governments and companies to REMOVE THE MASKS. This would allow the population to "see" the rates of pollution and their effects on human health and on climate. These hidden facts are compared with the function of the masks: these masks prevent a transfer from one individual to another by hiding body parts. The use of the masks is thus a necessary procedure to stop virus particles. Yet, the governments' and companies' decision to hide truth about pollution endangers human health. Activists rely on this paradox to ask governments and companies to tell the truth about pollution.

\subsection{ENVIRONMENTAL CONCERNS AS MEDICAL CONCERNS}

The effects of the pandemic on health workers are also acknowledged by XR. Activists published texts praising the messages of solidarity addressed to health workers. They transformed these messages into a tool for activists to express their environmental concerns. Activists show that environmental disruption could be addressed with similar solidarity. The "Letters of Love" campaign (Newsletter 38, 08/04/2020) encourages the population not only to send supporting words to health workers, but also to send "letters to the Earth". The Earth is no longer depicted as a SICK PATIENT but as an ESSENTIAL WORKER helping humanity to face threats. This campaign compares the essential role played by health workers during the pandemic with the essential role played by the Earth. The recent global support to health workers exemplifies the support that should be provided to the Earth.

The global focus on the essential role played by health workers during the pandemic shaded light on a specific category of "rebels", the "Doctors of XR". These rebels associate health concerns with environmental concerns. "Doctors of XR" represent a section of XR composed of health workers who are concerned about the impact of environmental damages on human health. In June 2020, these Doctors held a protest in Switzerland to 
demand more governmental support to health workers. This support could help them tackle the pandemic and it could prevent future health issues caused by environmental disruption and pollution. Protesters also criticised the government's financial support to polluting companies (e.g., Swiss airports) during the lockdown. In the video available on XR's website, we see protesters holding a banner emphasising the link between the symptoms of COVID-19 and the SYMPTOMS of the planet.

Figure 1: Doctors of XR - banner (Doctors4XR, Global Newsletter 39, 30/06/2020)

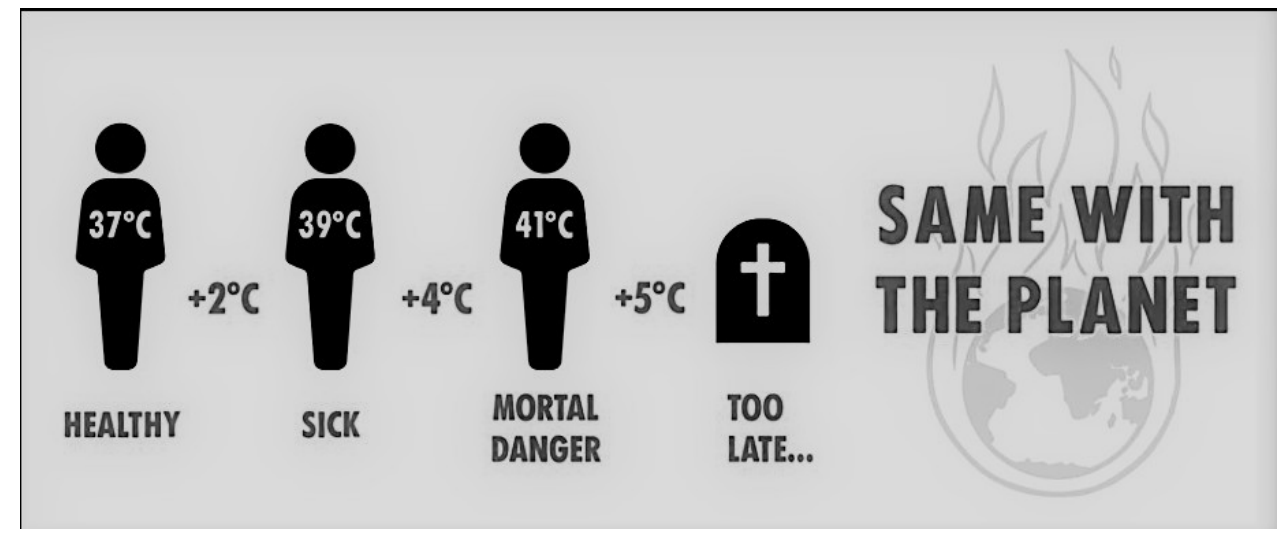

This visual metaphor does not explicitly mention that the increasing fever - illustrated through human shapes and different degrees (physiological and climatic) and different health conditions ("healthy", "sick", "mortal danger") - is associated with the pandemic. This association is inferred by the context of the protest which took place soon after the end of the lockdown in Switzerland. Hence, the impact of the pandemic and the health issues experienced by the population were still very relevant, and COVID-19 was still a major concern. The source domain FEVER thus echoes the current social anxiety. Doctors of XR establish a distressing graduation from healthy living conditions to death: this graduation compares humans' FEVER with the warming of the planet ("same with the planet"). The fever experienced by affected people only represents one of the symptoms of the Coronavirus and, therefore, the deaths related to COVID-19 cannot be exclusively explained by high fever. However, the playful association of physiological "degrees" with climatic "degrees" favours a metaphorical representation of the SYMPTOMS of the planet in terms of a FEVER. The lack of reference to COVID-19 emphasises that even though the pandemic has been partly mitigated, the SYMPTOMS of the planet still evolve. This banner also serves an explanatory function: Doctors have a deep knowledge concerning human health, and the Doctors of XR also have a deep knowledge concerning the effects of environmental disruption. This banner thus explains the risks associated with increasing temperatures, through the mapping CLIMATIC DEGREES AS DEGREES OF FEVER. The medical background of these "rebels" conveys additional legitimacy to environmental arguments: while medical skills have been praised during the pandemic, environmental skills are equally necessary for the prevention of future threats. The mapping CLIMATIC DEGREES AS DEGREES OF FEVER lets the recipients free to establish the consequences of these threats: these threats can be related to humans' health (e.g., future pandemics) or to the HEALTH OF THE PLANET (e.g., future warming). 
The pandemic and environmental issues share many characteristics. These characteristics allow activists to advertise a wide variety of arguments comparing climate change with COVID-19. For instance, XR's newsletter states:

"Neither COVID nor climate pay attention to borders. The world is a small place, and we are all interconnected. This is the basis of planetary health. Prevention is better than cure" (Newsletter 38, Lesley Morrison, 08/04/2020).

This extract highlights several characteristics shared by COVID-19 and climate change. Lesley Morrison describes the global consequences of the phenomena ("borders"), the consequences on all humans discarding nationality or social status ("we are all interconnected"), the dangerous effects on health ("planetary health"), and the acknowledgement of existing threats ("prevention"). The personification of COVID-19 and climate ("pay attention") adds an alarming stance to the extract: the two phenomena appear as an EVIL-MINDED TEAM and they seem to work together on the places and communities they affect. We can infer that this personification reveals the beginning of a crime storyline: both characters (climate and COVID-19) share dangerous features, they both target similar VICTIMS, and the CRIME SCENES are similar. The alarmist stance in this extract is accentuated through the depictions of the world as "a small place" and of humanity as "interconnected" humans. These depictions counterbalance the non-threatening image of two EVIL-MINDED characters against a population of 7.8 billion people: these 7.8 billion people are "interconnected" and contained in a "small place", making it easier for the EVIL-MINDED TEAM to affect them all. The last sentences reassure readers by offering possible solutions. On the one hand, the phrase planetary health implies that interconnection can also promote solidarity to help people at risk. On the other hand, the last sentence "Prevention is better than cure" is shaped as a morale showing that the storyline is not real yet. This last sentence transforms the characterisation of COVID-19 and climate: these phenomena are no more depicted as an EVIL-MINDED TEAM, but as DISEASES which can be PREVENTED and CURED. Therefore, this extract first emphasises that the lack of prevention related to the COVID-19 pandemic has led to the realisation of a crime storyline (e.g., national lockdowns and global impact) but international actions softened its impact. Then, the association with climate - first personified as an EVILMINDED CHARACTER and then characterised as a PREVENTABLE DISEASE - warns recipients about the risks involved in the present lack of environmental mitigation. This characterisation represents an opportunity to prevent future global threats.

\section{Discussion}

XR's publications help us to compare the HEALTH metaphors used before and during the pandemic. Firstly, the source domains which are not associated with specific DISEASE/PAIN/SYMPTOM - such as healthy/ dying planet - are continuously used by XR. However, the context of the pandemic has re-shaped the interpretation of these metaphors. HEALTH metaphors unrelated to COVID-19 establish a link between the HUMAN BODY and the PLANET BODY. This link calls readers to take care of the planet in the same way they take care of themselves. In contrast, the HEALTH metaphors related to COVID-19 echo recent experiences of threats. These 
highlight more features related to the source domain HUMAN HEALTH, with emphasis such as "healthy people need healthy environment". This instance first literally describes human health ("healthy people") and then relies on HEALTH as a source domain ("healthy environment"). This emphasis recalls the distress readers experienced during the pandemic regarding their own health. It promotes a similar distress regarding the effects of an UNHEALTHY environment.

Secondly, AGGRESSION/MURDER metaphors also occurred before and during the pandemic. However, the pandemic has also re-shaped the metaphorical interpretation. The metaphorical ANTAGONISTIC relationship between nature and polluters, polluting sectors, industries, or governments has transformed into an ANTAGONISTIC relationship between humanity as a whole, and COVID-19 and climate change. The evolution of the metaphorical interpretation is caused by the global acknowledgement regarding the negative effects of COVID-19. XR states that the virus and climate change may ATTACK HUMANS AND THE PLANET (planetary health). Accordingly, XR compares the global actions taken against the virus with the actions that should be taken against climate change. This comparison helps activists to convince readers not to stop actions.

Thirdly, two themes related to the source domain HEALTH have emerged during the pandemic: on the one hand, the increasing attention to safety measures has promoted the use of different HEALTH metaphors. The new global cautiousness highlights different features of the ECOSYSTEM HEALTH metaphor, which readers would not have decoded in the same way before the pandemic. For example, the (UN)MASK metaphor has more implications when people are asked to wear masks for safety than when the pandemic was not declared. This metaphor can still be interpreted without reference to COVID-19, but it takes on a wider variety of implications during the pandemic (e.g., people's negative opinion about not wearing a mask or not wearing a mask appropriately is used to criticise polluting industries, sectors, and governmental bailouts).

On the other hand, the increasing attention to the problems experienced in the health sector has also promoted new views on the ECOSYSTEM HEALTH. While the lockdown prevented the spread of the virus to avoid overcrowded hospitals, health workers have received global messages of gratitude. Accordingly, this largescale demonstration of gratitude has supplemented the descriptions of the ECOSYSTEM HEALTH. XR has relied on the population's acknowledgement regarding the essential role of health workers: they compared the role played by health workers with the role played by the planet. Health workers were also involved in the metaphorical mappings produced before the pandemic (e.g., "Guardians of life"), but the feeling of gratitude was only established between the DYING PATIENT and the NURSE with whom viewers were expected to identify. During the pandemic, XR's campaign "Letters to the Earth" calls for global gratitude supporting the Earth during a difficult period. The MEDICAL features of the ECOSYSTEM HEALTH have taken on additional implications: the Earth is not only a HOSPITALISED PATIENT, it also transforms into an ESSENTIAL WORKER.

This paper demonstrates a revitalisation of the ECOSYSTEM HEALTH metaphor (Goatly 1997). Even though some aspects of HEALTH metaphors were already observed before the pandemic - like (UN)HEALTHY PLANET, DYING PLANET, and MEDICAL SETTINGS -, references to COVID-19 promote a wider variety of implications which were more salient during the pandemic. This revitalisation can be established at the level of interpretation: we identify arguments promoted by the use of specific metaphors which refer to the recent threat and safety measures (wearing masks, washing hands). Some of these safety measures were taken for granted before the pandemic (e.g., washing hands), but information about COVID-19 revealed the importance of these measures. HEALTH metaphors used by XR referred to these important measures to raise awareness about the 
virus and about climate change and pollution.

Additionally, the link between ECOSYSTEM HEALTH and HUMAN HEALTH has been "foregrounded". While XR's main concerns remain environmental, activists did not ignore people's distress regarding their own health. This distress resonates in the use of HEALTH metaphors during the pandemic: argumentative strategies such as the lack of identification of the planet's DISEASE, and the depiction of humanity suffering from a similar AGGRESSION performed by COVID-19 and climate change advertise a relation between human health and environmental concerns. Before the pandemic, XR called for environmental actions to RESCUE THE PLANET whereas during the pandemic, the focus was on environmental actions to RESCUE HUMANITY. This changing focus was only possible because the pandemic revealed that human health cannot be taken for granted.

However, HEALTH metaphors in publications from XR do not promote metaphorical identifications such as CLIMATE CHANGE AS COVID-19. While the phenomena share many characteristics, such a metaphor contradicts XR's arguments: it would imply that the end of the pandemic is related to the end of climate change. Even though some metaphors depict COVID-19 and climate change as similar threats to humanity, both phenomena preserve their respective identities. This limited comparison informs about remaining threats that humanity has to face.

\section{Conclusion}

This paper establishes the arguments promoted by HEALTH metaphors in publications from XR. The ECOSYSTEM HEALTH metaphor is grounded in common knowledge about human health, but the pandemic has transformed this common knowledge. HEALTH metaphors have subsequently highlighted characteristics of human health which were either taken for granted before the pandemic or which were revealed following the unprecedented impact of the pandemic (e.g., wearing masks).

The references to COVID-19 in the use of metaphors in publications from XR can be unsurprising, acknowledging the global concerns related to this recent threat. For example, we can observe COVID-19 metaphors describing climate change in The New York Times or in publications from international NonGovernmental Organisations like the Asia Foundation. We looked at publications from other environmental organisations like Greenpeace and Friends of the Earth. Among the 41 publications from Greenpeace and the 14 publications from Friends of the Earth which all discuss the pandemic, a single HEALTH metaphor has been observed: the green recovery (e.g., "A green and fair recovery should be the centrepiece of the government plans", Friends of the Earth, 30/06/2020). However, this metaphor cannot be associated with the pandemic if we acknowledge the central part of the concept green recovery in the United Nations Environment Programme released in 2009 ("Global green new deal").

This comparison between XR and other environmental organisations demonstrates the particularities of XR. The disruption and the eye-catching characteristics of XR's protests are at the heart of XR's communicative strategies. The particularities of these protests can promote interest not only from decision makers but also from the population. The readership addressed in XR's publications cannot be restricted to activists, or people concerned about climate change: these are also addressed to people whose curiosity has been triggered following such protests. XR attracts greater media attention (1,687 British newspaper articles about XR between January $1^{\text {st }}$ and July $\left.1^{\text {st }}, 2020\right)$ compared with Greenpeace (858 articles) and Friends of the Earth (691 articles): the 
journalistic descriptions of XR's protests yield popular attention towards the organisation.

Publications have been attributed a new central role in XR's communication during the pandemic. We can assume that the reliance on COVID-19 metaphors illustrates a changing communicative strategy. These metaphors take into account people's daily life: the arguments rely on individuals' responsibility to stay home, wear masks, wash hands to protect the health sectors, and promote similar responsibility to protect the planet. Even though XR's reliance on COVID-19 metaphors did not prevent a decrease of media attention during the pandemic, these metaphors show that XR's communication has not only adapted to the impossibility for activists to protest, but also to the impossibility for the population to perform out-of-door activities. Our paper demonstrates that COVID19 metaphors used by XR fulfil a specific function: they inform readers about environmental actions which can be performed at home.

The author has reported no conflict of interest

Data available at: https://rebellion.earth/news/

\section{References}

Atanasova, D. \& Koteyko, N. (2017). 'Metaphors in The Guardian online and The Mail online opinion-page content on climate change: war, religion, and politics'. Environmental Communication 11(4): 452-469.

Augé, A. (2019). 'How metaphor scenarios can reveal socio-cultural and linguistic variations of meaning: a crosslinguistic perspective on the "NURTURING PARENT" and the "STRICTFATHER" frames'. Metaphor and Symbol 34(4): 209-228.

Charteris-Black, J. (2004). Corpus Approaches to Critical Metaphor Analysis. London, Palgrave Macmillan.

Extinction Rebellion (News section): URL: https://rebellion.earth/news/

Flusberg, S.-J., Matlock, T. \& Thibodeau, P.-H. (2017). 'Metaphors for the war (or race) against climate change'. Environmental Communication 11(6): 769-783.

Foust, C.-R. \& Murphy, W.-OS. (2009). 'Revealing and reframing apocalyptic tragedy in global warming discourse'. Environmental Communication 3(2): 151-167.

Friends of the Earth. URL: https://www.foe.org

Goatly, A. (1997). The Language of Metaphors. London and New York, Routledge.

Greenpeace. URL: https://www.greenpeace.org.uk/

Kilgarriff A. (2014). SketchEngine, URL: https://www.sketchengine.eu/ (accessed June 2020)

Koteyko, N. (2010). "Mining the internet for linguistic and social data: an analysis of "carbon compounds" in web feeds'. Discourse \& Society 21(6): 655-674.

Koteyko, N., Thelwall, M. \& Nerlich, B. (2009). 'From carbon markets to carbon morality: creative compounds as framing devices in online discourses on climate change mitigation'. Science Communication 32(1): 25-54. 
Lakoff, G. (1993) [1979]. 'The contemporary theory of metaphor'. In Ortony, A. (ed) Metaphor and Thought. Cambridge, Cambridge University Press: 202-252.

Larson, B. (2011). Metaphors of Environmental Sustainability: Redefining our relationship with Nature. New Haven and London : Yale University Press.

Musolff, A. (2016). Political Metaphor Analysis: Discourse and Scenarios. London, Bloomsbury Academic.

Nerlich, B. (2010). “'ClimateGate”: paradoxical metaphors and political paralysis'. Environmental Values 14 (9): 419-442.

Nerlich, B. \& Hellsten, I. (2014). 'The greenhouse metaphor and the footprint metaphor: climate change risk assessment and risk management seen through the lens of two prominent metaphors'. Technikfolgenabschatzung: Theorie und Praxis 23(2): 27-33.

Nexis (n.d.). URL: www.nexis.com

Oxford English Dictionary (online version). URL: www.oed.com

Rapport, D. (1995). 'Ecosystem health : more than a metaphor ?' Environmental Values 4 : 287-309.

Ross, N. et al. (1997). 'The ecosystem health metaphor in science and policy'. The Canadian Geographer 41(2) : 114-27.

Steen, G.-J. et al. (2010). A Method for Linguistic Metaphor Identification. Amsterdam, John Benjamins.

Tognini Bonelli E. (2001). Corpus Linguistics at work. Amsterdam, John Benjamins.

United Nations Environment Programme (2009). 'Global green new deal'. URL: https://www.unenvironment.org/resources/annual-report/unep-2009-annual-report 